\title{
Association Between ApoAI Gene Polymorphisms and Antipsychotic Drug-Induced Dyslipidemia in Schizophrenia
}

\author{
Lin Fan ${ }^{1, *}$ \\ Yiwen You ${ }^{1} *$ \\ Yao Fan $^{2}$ \\ Chong Shen ${ }^{3}$ \\ Yong Xue $\mathbb{D}^{4}$
}

'Department of Pharmacy, Huai'an Third People's Hospital, Huai'an, People's Republic of China; ${ }^{2}$ Division of Clinical Epidemiology, Affiliated Geriatric Hospital of Nanjing Medical University, Nanjing, People's Republic of China; ${ }^{3}$ Department of Epidemiology, School of Public Health, Nanjing Medical University, Nanjing, People's Republic of China; ${ }^{4}$ Department of Medical Laboratory, Huai'an Third People's Hospital, Huai'an, People's Republic of China

*These authors contributed equally to this work
Correspondence: Yong Xue

Department of Medical Laboratory,

Huai'an Third People's Hospital, Huai'an,

People's Republic of China

Tel +86 I386I5831/8

Email xueyong3@126.com
Purpose: Dyslipidemia frequently occurs in schizophrenia patients treated with antipsychotic drugs (APDs), especially atypical APDs. Apolipoprotein A1 (ApoA1) plays a key role in lipid metabolism. The aim of this study was to investigate whether ApoA1 gene polymorphisms are associated with APD-induced dyslipidemia in schizophrenia patients.

Patients and Methods: A total of 1987 patients with schizophrenia were enrolled in this study. Serum lipid profiles were determined with a biochemistry analyzer. Genotyping for the rs5072 polymorphism of ApoA1 was performed with TaqMan assay. Logistic regression analysis was carried out to evaluate the relationship between ApoA1 gene polymorphisms and APDinduced dyslipidemia. The effects of drug classification (typical vs atypical APD) and drug regimen (monotherapy vs combination therapy) on serum lipid levels were also analyzed.

Results: A significant association was found between rs5072 and triglyceride (TG) levels in the recessive model of the logistic regression analysis (adjusted odds ratio $[\mathrm{OR}]=1.50,95 \%$ confidence interval $[\mathrm{CI}]: 1.03,2.17 ; \mathrm{P}<0.05)$. TG level was significantly higher in patients treated with combination therapy $(1.03(0.71,1.51) \mathrm{mmol} / \mathrm{l})$ compared to monotherapy $(0.93$ $(0.67,1.43) \mathrm{mmol} / \mathrm{l})$ and was also associated with sex. There were significant differences in TG levels among the three genotypes of ApoA1 rs5072 (GG, GA, and AA) in the whole study population and in patients treated with atypical APDs.

Conclusion: The ApoA1 rs5072 variant is associated with dysregulated TG metabolism in schizophrenia patients treated with APDs, which may increase susceptibility to dyslipidemia.

Keywords: apolipoprotein A1, gene polymorphism, dyslipidemia, schizophrenia, antipsychotic drug

\section{Introduction}

Schizophrenia is a complex mental disorder characterized by positive and negative symptoms including delusions, hallucinations, thought disorder, apathy, and avolition as well as cognitive and functional impairment. ${ }^{1,2}$ Schizophrenia affects approximately $1 \%$ of the world's population ${ }^{1,3}$ and the lifetime risk of developing schizophrenia is $\sim 0.7 \%$. ${ }^{4}$ Despite its relatively low prevalence, schizophrenia is a significant burden on the healthcare system; in 2016, the global disease burden of schizophrenia was 13.4 (95\% uncertainty interval: 9.9-16.7) million years of life lived with disability. ${ }^{5}$

Antipsychotic drugs (APDs) are the first-line treatment for schizophrenia. ${ }^{4}$ Chlorpromazine is a representative typical APD; atypical APDs include 
clozapine, olanzapine, risperidone, and quetiapine. ${ }^{6}$ Although they are known to be effective in the treated of schizophrenia, these drugs - especially atypical APDs - can cause metabolic dysfunction including dyslipidemia, weight gain, insulin resistance, and glucose intolerance. $^{7}$ While monotherapy is the recommended regimen, given the complexity of the disease, combination therapy (ie, concurrent use of two or more APDs) is often prescribed. ${ }^{8}$ However, this is associated with increased risks of metabolic syndrome and insulin resistance compared to treatment with a single drug, ${ }^{9}$ although the underlying mechanisms are not known.

Dyslipidemia, which is among the most common side effects of APDs in schizophrenia patients, ${ }^{10}$ is characterized by abnormal lipid levels such as increases in total cholesterol (TC), triglycerides (TGs), and lowdensity lipoprotein cholesterol (LDL-C) and a decrease in high-density lipoprotein cholesterol (HDL-C). ${ }^{11}$ As most schizophrenia patients require lifelong treatment, the risk of dyslipidemia is a major concern associated with APD maintenance treatment. Sterol regulatory element-binding protein has been implicated in dyslipidemia induced by atypical APDs. ${ }^{12}$ Activation of hypothalamic AMP kinase via histamine $\mathrm{H}_{1}$ receptor was shown to contribute to APD-induced weight gain through modulation of food intake. ${ }^{13}$ Additionally, polymorphisms in the promoter region of the $5-\mathrm{HT}_{2 \mathrm{C}}$ receptor gene were found to be closely related to weight gain in first-episode psychosis. ${ }^{14}$

Apolipoprotein (Apo) A1 is a key component of high-density lipoprotein (HDL), which is involved in reverse cholesterol transport and promotes cholesterol efflux from tissues and excretion in the liver. ${ }^{15}$ ApoA1 level was reported to be reduced in schizophrenia patients compared to healthy subjects, ${ }^{16}$ and was upregulated following treatment with APDs. ${ }^{17}$ However, the precise role of ApoA1 in schizophrenia is poorly understood.

The occurrence of schizophrenia is strongly influenced by genetic factors. ${ }^{4,18}$ ApoA1 is encoded by the ApoA1 gene located on chromosome 11q23, which is an area of interest in schizophrenia research; $;^{19,20}$ single nucleotide polymorphisms (SNPs) of this gene have been identified in patients. ${ }^{21,22}$ The present study investigated the relationship between ApoAl gene polymorphisms and dyslipidemia induced by APDs in schizophrenia.

\section{Patients and Methods}

\section{Subjects}

A total of 1979 schizophrenia inpatients treated at Huai'an Third People's Hospital in Huai'an, China between 2010 and 2018 were enrolled in this study. Schizophrenia was diagnosed according to the Chinese Classification and Diagnosis of Mental Diseases 3rd Edition. Patients with cardiovascular or cerebral vascular disease, liver disease, nephropathy, and/or immunologic diseases were excluded. A standard questionnaire was administered to collect demographic data on schizophrenia patients such as sex, age, family history, etc. This study was approved by the Research Ethics Committee of Huai'an Third People's Hospital (approval no. 2018003) and was conducted in accordance with the principles of the Declaration of Helsinki. All patients signed the consent form after being informed of the study protocol.

\section{Biochemical Measurements}

Venous blood samples were collected from patients between 8 a.m. and 9 a.m. after a 12-h overnight fast. Serum TC, TG, LDL-C, and HDL-C levels were measured by enzymatic methods. ApoA1 and ApoB levels in blood samples were detected with a turbidimetric inhibition immunoassay performed with an Automatic Biochemical Analyzer (AU5800, Beckman Coulter, Inc., Brea, CA, USA).

\section{SNP Selection}

The ApoA1 gene (gene ID: 335 ) is located on chromosome 11q23.3 and spans $2.2 \mathrm{~kb}(116835751-116837950 \mathrm{bp})$. SNPs of the ApoA1 gene in the Chinese Han population from Beijing, China (CHB) were searched in the HapMap database. Tagging SNPs (tagSNPs) of ApoA1 were searched in the CHB data of HapMap (dbSNP b126); and 6 SNPs (rs5072, rs2070665, rs10750098, rs632153, rs12718462, and rs12718464) within the region from $2 \mathrm{~kb}$ upstream to 1 $\mathrm{kb}$ downstream of the ApoA1 gene along with the selected tagSNPs were searched in the Genome Variation Server 147 (http://gvs.gs.washington.edu/GVS147/). All selected tagSNPs met the following criteria: minor allele frequency $\geq 0.05$ and linkage disequilibrium value of $r^{2} \geq 0.8$. A candidate screening strategy was used to identify SNPs with functions in transcription, gene regulation, splicing, etc. using the Function Analysis and Selection Tool for Single Nucleotide Polymorphisms web server (http://fastsnp.ibms. sinica.edu.tw). One tagSNP, rs5072, was selected from the genotyping experiments for further analysis (Table S1). 


\section{DNA Isolating and Genotyping}

Blood samples were collected in ethylenediaminetetraacetic acid-containing tubes. DNA was extracted from peripheral blood leukocytes by proteinase $\mathrm{K}$ digestion and the phenol-chloroform method. The TaqMan SNP Genotyping Assay was used for genotyping; we repeated the genotyping for $5 \%$ of samples (randomly selected) for quality control. The call rates of the SNPs were $>99 \%$.

\section{Statistical Analysis}

Data were analyzed with SPSS v19.0 software (SPSS Inc, Chicago, IL, USA). The Kolmogorov-Smirnov test was used to assess the distribution of variables. Normally distributed data are presented as mean \pm standard deviation and were analyzed with a two-tailed Student's $t$ test. Quantitative variables with non-normal distribution are expressed as median and interquartile range, and comparisons between groups were performed with nonparametric tests. Categorical variables were analyzed with the chisquared $\left(\chi^{2}\right)$ test or Fisher's exact test. Logistic regression analysis was carried out to evaluate the association between ApoA1 gene polymorphisms and dyslipidemia. A $\mathrm{P}$ value $<0.05$ was defined as statistically significant.

\section{Results}

\section{Demographic and Clinical Characteristics of the Study Population}

A total of 1979 inpatients (902 males [45.58\%] and 1077 females [54.42\%]) diagnosed with schizophrenia were included in this study; their demographic and clinical characteristics and biochemical data (serum lipids levels) are shown in Table 1 . The mean age was $34.37 \pm 12.90$ years. A total of $99(5.00 \%)$ patients were treated with typical APDs; 1476 (74.58\%) were treated with atypical APDs; and 404 (20.42\%) were treated with a combination of typical and atypical APDs. In terms of treatment regimen, $57.91 \%$ of patients received antipsychotic monotherapy and $42.09 \%$ received combination therapy.

\section{Relationship Between Therapeutic Regimen and Serum Lipid Levels}

Serum TG level was higher with APD combinations (1.03 $(0.71,1.51) \mathrm{mmol} / \mathrm{l})$ than with monotherapy $(0.93$ $(0.67,1.43) \mathrm{mmol} / \mathrm{l})$. There were no significant differences in the levels of other lipids between the groups (Table 2). Stratification by sex revealed that the difference in TG levels between combination therapy and
Table I Demographic and Clinical Characteristics of Cases

\begin{tabular}{|l|l|l|}
\hline Characteristics & Group & $\begin{array}{l}\text { Cases } \\
(\mathbf{n}=1979)\end{array}$ \\
\hline Sex & $\begin{array}{l}\text { Male } \\
\text { Female }\end{array}$ & $\begin{array}{l}902(45.58 \%) \\
1077(54.42 \%)\end{array}$ \\
\hline Age, years & & $34.37 \pm 12.90$ \\
\hline Family history & $\begin{array}{l}\text { Positive } \\
\text { Negative }\end{array}$ & $\begin{array}{l}403(20.36 \%) \\
1576(79.63 \%)\end{array}$ \\
\hline Drug regimen & $\begin{array}{l}\text { Monotherapy } \\
\text { Combination therapy }\end{array}$ & $\begin{array}{l}1146(57.91 \%) \\
833(42.09 \%)\end{array}$ \\
\hline Drug classification & $\begin{array}{l}\text { Typical } \\
\text { Atypical } \\
\text { Combined (typical and }\end{array}$ & $\begin{array}{l}99(5.00 \%) \\
1476(74.58 \%)\end{array}$ \\
\hline atypical)
\end{tabular}

Notes: Data are shown as mean \pm standard deviation, median (interquartile range) or $\mathrm{n}$ (\%). Lipid levels showed a skewed distribution according to the KolmogorovSmirnov test and are expressed as median (interquartile range).

Abbreviations: ApoAI, apolipoprotein AI; ApoB, apolipoprotein B; HDL, highdensity lipoprotein; HDL-C, high-density lipoprotein cholesterol; LDL-C, lowdensity lipoprotein cholesterol; TC, total cholesterol; TG, triglyceride.

monotherapy was only present in female patients $(1.00(0.70,1.48) \mathrm{mmol} / \mathrm{l}$ vs $0.91(0.65,1.39) \mathrm{mmol} /$ 1) (Table 3).

Table 2 Comparison of Serum Lipid Levels Between Patients Treated with Antipsychotic Monotherapy and Combination Therapy

\begin{tabular}{|l|l|l|l|l|}
\hline $\begin{array}{l}\text { Serum } \\
\text { Lipid, } \\
\text { mmol/I }\end{array}$ & $\begin{array}{l}\text { Monotherapy } \\
\text { (n=I I 46) }\end{array}$ & $\begin{array}{l}\text { Combination } \\
\text { Therapy (n=832) }\end{array}$ & $\mathbf{Z}$ & $\boldsymbol{P}^{\mathbf{a}}$ \\
\hline TC & $3.94(3.37,4.62)$ & $4.00(3.4 I, 4.62)$ & 1.11 & 0.27 \\
TG & $0.93(0.67, I .43)$ & $1.03(0.7 I, I .5 I)$ & 2.71 & 0.01 \\
LDL-C & $2.60(2.12,3.14)$ & $2.68(2.15,3.18)$ & 0.92 & 0.36 \\
HDL-C & $1.17(1.00,1.36)$ & $1.15(1.00,1.36)$ & 0.45 & 0.65 \\
\hline
\end{tabular}

Notes: ${ }^{a}$ Mann-Whitney $U$ non-parametric testing was used to compare nonnormally distributed quantitative variables between antipsychotic monotherapy and combination therapy groups.

Abbreviations: HDL-C, high-density lipoprotein cholesterol; LDL-C, low-density lipoprotein cholesterol; TC, total cholesterol; TG, triglyceride. 
Table 3 Comparison of Serum Lipid Levels Between Patients Treated with Antipsychotic Monotherapy and Combination Therapy Stratified by Sex

\begin{tabular}{|c|c|c|c|c|c|}
\hline Sex & Serum Lipid, mmol/l & Monotherapy & Combination therapy & $\mathbf{z}$ & $P^{a}$ \\
\hline \multirow[t]{4}{*}{ Male $(548 / 353)$} & TC & $3.90(3.35,4.65)$ & $3.98(3.38,4.63)$ & 0.67 & 0.50 \\
\hline & TG & $0.97(0.69,1.50)$ & $1.06(0.75,1.56)$ & 1.83 & 0.07 \\
\hline & LDL-C & $2.66(2.17,3.20)$ & $2.70(2.17,3.20)$ & 0.26 & 0.80 \\
\hline & HDL-C & I.I2 (0.99, I.3I) & I.I3 (0.98, I.34) & 0.14 & 0.89 \\
\hline \multirow[t]{4}{*}{ Female $(598 / 479)$} & TC & $3.95(3.39,4.59)$ & $4.0 \mathrm{I}(3.47,4.58)$ & 0.87 & 0.38 \\
\hline & TG & $0.91(0.65,1.39)$ & $1.00(0.70,1.48)$ & 2.18 & 0.03 \\
\hline & LDL-C & $2.56(2.08,3.08)$ & $2.66(2.13,3.15)$ & 1.16 & 0.24 \\
\hline & HDL-C & $1.20(1.01,1.42)$ & $1.18(1.00,1.38)$ & 1.13 & 0.26 \\
\hline
\end{tabular}

Notes: ${ }^{a}$ Mann-Whitney $U$ non-parametric testing was used to compare non-normally distributed quantitative variables between antipsychotic monotherapy and combination therapy groups.

Abbreviations: HDL-C, high-density lipoprotein cholesterol; LDL-C, low-density lipoprotein cholesterol; TC, total cholesterol; TG, triglyceride.

\section{Relationship Between APD Classification and Serum Lipid Levels}

The patients were divided into three groups according to APD classification (ie, typical, atypical, and combined typical and atypical APD). Lipid levels did not differ among the three groups (Table 4) or between the typical and atypical groups (Table 4).
Stratification by sex revealed no significant differences (Table 5).

\section{Association Between ApoAl Polymorphism and Dyslipidemia}

Dyslipidemia was defined according to the Guidelines on Prevention and Treatment of Dyslipidemia in Chinese

Table 4 Comparison of Serum Lipid Levels Between Patients Treated with Typical and Atypical Antipsychotic Drugs and Their Combination

\begin{tabular}{|c|c|c|c|c|c|c|c|}
\hline Serum Lipid, mmol/l & Typical $(n=99)$ & Atypical $(n=\mid 476)$ & Combined $(n=403)$ & $\mathbf{Z}$ & $P^{a}$ & $\mathbf{Z}$ & $P^{b}$ \\
\hline $\mathrm{TC}$ & $4.09(3.38,4.78)$ & $3.95(3.39,4.60)$ & $3.99(3.40,4.63)$ & 0.83 & 0.66 & 0.86 & 0.39 \\
\hline TG & $1.01(0.74,1.63)$ & $0.96(0.67,1.48)$ & $1.00(0.70,1.40)$ & 1.14 & 0.57 & 1.04 & 0.30 \\
\hline LDL-C & $2.57(2.26,3.28)$ & $2.62(2.12,3.15)$ & $2.67(2.15,3.16)$ & 0.98 & 0.61 & 0.74 & 0.46 \\
\hline HDL-C & $1.17(1.00,1.34)$ & $1.16(1.00,1.35)$ & $1.18(1.00,1.4 \mathrm{I})$ & 1.65 & 0.44 & 0.25 & 0.81 \\
\hline
\end{tabular}

Notes: ${ }^{a}$ Brown-Mood non-parametric testing was used to compare non-normally distributed quantitative variables among typical, atypical and combined antipsychotic drug groups. 'Mann-Whitney $U$ non-parametric testing was used to compare non-normally distributed quantitative variables between typical and atypical antipsychotic drug groups.

Abbreviations: HDL-C, high-density lipoprotein cholesterol; LDL-C, low-density lipoprotein cholesterol; TC, total cholesterol; TG, triglyceride.

Table 5 Comparison of Serum Lipid Levels Between Patients Treated with Typical and Atypical Antipsychotic Drugs and Their Combination Stratified by Sex

\begin{tabular}{|c|c|c|c|c|c|c|c|c|}
\hline Sex & Serum Lipid, mmol/l & Typical & Atypical & Combined & $\mathbf{Z}$ & $P^{a}$ & $\mathbf{Z}$ & $P^{b}$ \\
\hline \multirow[t]{4}{*}{ Male $(56 / 665 / / 80)$} & $\mathrm{TC}$ & $3.97(3.36,4.64)$ & $3.95(3.37,4.65)$ & $3.90(3.31,4.63)$ & $0.4 I$ & 0.81 & 0.24 & 0.81 \\
\hline & TG & $1.03(0.80,1.66)$ & $1.00(0.7 \mathrm{I}, \mathrm{I} .52)$ & I.0I $(0.72, I .4 \mathrm{I})$ & 1.12 & 0.57 & 1.02 & 0.31 \\
\hline & LDL-C & $2.56(2.22,3.29)$ & $2.72(2.19,3.20)$ & $2.57(2.12,3.19)$ & 1.25 & 0.53 & 0.13 & 0.90 \\
\hline & HDL-C & I.II $(0.95,1.34)$ & I.II $(0.99,1.30)$ & I.II $(1.00,1.37)$ & 3.60 & 0.17 & 0.22 & 0.83 \\
\hline \multirow[t]{4}{*}{ Female $(43 / 81 \mathrm{I} / 223)$} & $\mathrm{TC}$ & $4.26(3.38,5.06)$ & $3.94(3.40,4.57)$ & $4.06(3.49,4.64)$ & 3.30 & 0.19 & 1.51 & 0.13 \\
\hline & TG & $0.92(0.70,1.32)$ & $0.93(0.66,1.43)$ & $0.97(0.69,1.39)$ & 0.27 & 0.87 & 0.25 & 0.81 \\
\hline & LDL-C & $2.59(2.26,3.28)$ & $2.56(2.07,3.08)$ & $2.70(2.15,3.16)$ & 4.82 & 0.09 & 0.96 & 0.33 \\
\hline & HDL-C & $1.22(1.06,1.39)$ & $1.19(1.00,1.39)$ & $1.19(1.00,1.42)$ & 0.78 & 0.68 & 0.88 & 0.38 \\
\hline
\end{tabular}

Notes: ${ }^{a}$ Brown-Mood non-parametric testing was used to compare non-normally distributed quantitative variables among typical, atypical, and combined antipsychotic drug groups. ' Mann-Whitney $U$ non-parametric testing was used to compare non-normally distributed quantitative variables between typical and atypical antipsychotic drug groups. Abbreviations: HDL-C, high-density lipoprotein cholesterol; LDL-C, low-density lipoprotein cholesterol; TC, total cholesterol; TG, triglyceride. 
Table 6 Association Between the ApoAI rs5072 Genotype and Serum Lipid Levels

\begin{tabular}{|c|c|c|c|c|}
\hline \multirow[t]{2}{*}{ Serum Lipid } & \multirow{2}{*}{$\begin{array}{l}\text { Genotype } \\
\text { GG/GA/AA }\end{array}$} & \multicolumn{3}{|l|}{ OR $(95 \% \mathrm{Cl})^{\mathrm{a}}$} \\
\hline & & Addictive & Dominant & Recessive \\
\hline $\mathrm{TC}<5.2 \mathrm{mmol} / \mathrm{l}$ & $876 / 710 / 152$ & I.08 (0.87-I.33) & I.0I (0.76-I.33) & $1.38(0.89-2.16)$ \\
\hline $\mathrm{TC} \geq 5.2 \mathrm{mmol} / \mathrm{l}$ & $120 / 87 / 27$ & $P=0.50$ & $P=0.95$ & $P=0.15$ \\
\hline $\mathrm{TG}<1.7 \mathrm{mmol} / \mathrm{l}$ & $818 / 656 / 136$ & I.I5 (0.97-I.37) & $1.10(0.88-1.39)$ & $1.50(1.03-2.17)$ \\
\hline $\mathrm{TG} \geq 1.7 \mathrm{mmol} / \mathrm{l}$ & $|78 /| 4 \mid / 43$ & $P=0.11$ & $P=0.40$ & $P=0.03$ \\
\hline LDL-C $<3.4 \mathrm{mmol} / \mathrm{l}$ & $837 / 688 / 148$ & $0.99(0.81-1.20)$ & $0.92(0.7 \mid-1.18)$ & $1.22(0.80-1.86)$ \\
\hline LDL-C $\geq 3.4 \mathrm{mmol} / \mathrm{I}$ & $|59 / 109 / 3|$ & $P=0.91$ & $P=0.49$ & $P=0.35$ \\
\hline $\mathrm{HDL}-\mathrm{C} \geq 1.0 \mathrm{mmol} / \mathrm{l}$ & $235 /|78 / 4|$ & $1.05(0.89-1.23)$ & $1.08(0.87-1.33)$ & I.0I (0.70-I.45) \\
\hline $\mathrm{HDL}-\mathrm{C}<1.0 \mathrm{mmol} / \mathrm{l}$ & $761 / 618 / 138$ & $P=0.58$ & $P=0.49$ & $P=0.97$ \\
\hline
\end{tabular}

Note: ${ }^{a}$ Logistic regression with adjustment for age, sex, drug classification and drug regimen.

Abbreviations: ApoAI, apolipoprotein AI; HDL-C, high-density lipoprotein cholesterol; LDL-C, low-density lipoprotein cholesterol; TC, total cholesterol; TG, triglyceride; $\mathrm{OR}$, odds ratio; $\mathrm{Cl}$, confidence interval.

Adults (2016 Revision) $)^{23}$ as high TC ( $\left.\geq 5.2 \mathrm{mmol} / \mathrm{l}\right)$, TG $(\geq 1.7 \mathrm{mmol} / \mathrm{l})$, and LDL-C $(\geq 3.4 \mathrm{mmol} / \mathrm{l})$ and low HDL-C $(<1.0 \mathrm{mmol} / \mathrm{l})$. SNP rs5072 of the ApoA1 gene was significantly associated with TG level after adjusting for covariates in the recessive model $(\mathrm{OR}=1.50,95 \% \mathrm{CI}$ : 1.03, 2.17; $\mathrm{P}=0.03$ ) (Table 6).

\section{Relationship Between ApoAl rs5072 and Serum Lipid Levels}

In the whole study population, the TG levels with the GG, GA, and AA genotypes of ApoA1 rs5072 were 0.95 (0.67, 1.44) $\mathrm{mmol} / \mathrm{l}, 1.00(0.70,1.42) \mathrm{mmol} / \mathrm{l}$, and $1.15(0.80$, 1.68) $\mathrm{mmol} / \mathrm{l}$, respectively; the differences among the three groups were statistically significant (Table 7). The TG levels with the GG, GA, and AA genotypes were 0.99 $(0.70,1.43) \mathrm{mmol} / \mathrm{l}, 1.06(0.72,1.53) \mathrm{mmol} / \mathrm{l}$, and 1.24 $(0.82,1.77) \mathrm{mmol} / \mathrm{l}$, respectively, in patients who received combination APD therapy and $0.91(0.65,1.47) \mathrm{mmol} / \mathrm{l}$, $0.95(0.68,1.37) \mathrm{mmol} / \mathrm{l}$, and $1.08(0.73,1.66) \mathrm{mmol} / \mathrm{l}$, respectively, in patients who received monotherapy. Within-group comparisons showed no significant differences in TG levels according to genotype, even after stratification by sex (data not shown).

Lipid levels in each genotype were also compared according to the type of APD. TG levels differed significantly among the three genotypes only in patients treated with atypical APDs $(\mathrm{P}=0.02)$, with values of $0.93(0.67$, $1.50) \mathrm{mmol} / \mathrm{l}, 0.97(0.67,1.41) \mathrm{mmol} / \mathrm{l}$, and $1.08(0.80$, 1.67) $\mathrm{mmol} / \mathrm{l}$, respectively, for the GG, GA, and AA genotypes (Table 7). Stratification analysis by sex showed that TC levels were significantly among the three genotypes in males treated with typical APDs $(\mathrm{P}=0.001$; data not shown).

\section{Discussion}

The available APDs have variable efficacy in patients with schizophrenia. Combination treatment with more than one APD is commonly used ${ }^{24,25}$ as many patients with schizophrenia do not demonstrate a satisfactory response to a monotherapy. ${ }^{26}$ However, there is inadequate evidence for the efficacy and safety of APD combinations, ${ }^{26,27}$ and few studies have investigated whether the two types of regimen differentially affect lipid metabolism.

In this study we found that APD combinations were more likely to be associated with elevated serum lipid levels than monotherapy, especially in females, suggesting that they increase the risk of dyslipidemia. This is consistent with a previous study demonstrating that TG level was lower with APD monotherapy than with combination therapy $(134 \pm 81.3$ vs $144.6 \pm 83.8 \mathrm{mg} / \mathrm{dl})$, although the difference in that study was not statistically significant. ${ }^{9}$ The high overall drug dose of APD combinations can increase the incidence of adverse reactions, and drug interactions can lead to variability in serum drug concentrations. Additionally, drug combinations usually contain at least one atypical APD because of the superior efficacy of these drugs, although they are more likely to cause dyslipidemia than typical APDs. Nonetheless, antipsychotic combinations are a good option for patients who do not respond or have contraindications to clozapine. A previous study found that women were at greater risk for adverse reactions to antipsychotics (including dyslipidemia) than men, ${ }^{28}$ with a fat transport velocity in blood that was about two times higher and a greater change in TG levels after high-carbohydrate or high-fat feeding. ${ }^{29}$ Another possible explanation for the sex difference in susceptibility to increased TG levels is that blood levels of some 
Table 7 Comparison of Serum Lipid Levels Across Genotypes

\begin{tabular}{|c|c|c|c|c|c|c|}
\hline \multirow[t]{2}{*}{ Group } & \multirow[t]{2}{*}{ Serum Lipid, mmol/I } & \multicolumn{3}{|l|}{ Genotype } & \multirow[t]{2}{*}{$\mathbf{Z}$} & \multirow[t]{2}{*}{$P^{a}$} \\
\hline & & GG & GA & AA & & \\
\hline \multirow[t]{4}{*}{ Total $(996 / 796 / 179)$} & $\mathrm{TC}$ & $3.97(3.37,4.63)$ & $3.95(3.4 I, 4.57)$ & $4.00(3.44,4.75)$ & 0.58 & 0.56 \\
\hline & TG & $0.95(0.67,1.44)$ & $1.00(0.70, I .42)$ & $1.15(0.80,1.68)$ & 5.54 & $<0.01$ \\
\hline & LDL-C & $2.66(2.13,3.18)$ & $2.60(2.15,3.10)$ & $2.65(2.07,3.20)$ & 0.21 & 0.81 \\
\hline & HDL-C & $1.15(1.00,1.35)$ & $1.17(1.00,1.37)$ & $1.16(1.00,1.34)$ & 1.25 & 0.29 \\
\hline \multicolumn{7}{|l|}{ Drug regimen } \\
\hline \multirow[t]{4}{*}{ Monotherapy (576/462/103) } & TC & $3.95(3.35,4.62)$ & $3.89(3.39,4.53)$ & $4.01(3.34,4.90)$ & 1.21 & 0.55 \\
\hline & TG & $0.91(0.65,1.47)$ & $0.95(0.68,1.37)$ & $1.08(0.73,1.66)$ & 5.22 & 0.07 \\
\hline & LDL-C & $2.64(2.11,3.20)$ & $2.56(2.14,3.05)$ & $2.64(2.04,3.22)$ & 0.92 & 0.63 \\
\hline & HDL-C & $1.16(1.00,1.36)$ & $1.19(1.00,1.36)$ & $1.16(1.00,1.30)$ & 1.24 & 0.54 \\
\hline \multirow[t]{4}{*}{ Combination therapy $(420 / 334 / 76)$} & $\mathrm{TC}$ & $3.98(3.37,4.63)$ & $4.02(3.46,4.62)$ & $3.99(3.52,4.60)$ & 0.32 & 0.85 \\
\hline & TG & $0.99(0.70,1.43)$ & $1.06(0.72,1.53)$ & $1.24(0.82,1.77)$ & 5.74 & 0.06 \\
\hline & LDL-C & $2.68(2.15,3.17)$ & $2.66(2.15,3.17)$ & $2.69(2.08,3.20)$ & 0.13 & 0.94 \\
\hline & HDL-C & $1.14(1.00,1.35)$ & $1.17(1.00,1.38)$ & $1.16(1.00,1.37)$ & 1.03 & 0.60 \\
\hline \multicolumn{7}{|l|}{ Drug classification } \\
\hline \multirow[t]{4}{*}{ Typical (52/39/8) } & $\mathrm{TC}$ & $4.18(3.56,4.87)$ & $3.74(3.18,4.46)$ & $3.50(3.00,5.35)$ & 3.35 & 0.19 \\
\hline & TG & I.0I $(0.72,1.43)$ & I. $10(0.76,1.73)$ & $\mathrm{I} .03(0.59,4.0 \mathrm{I})$ & 0.27 & 0.87 \\
\hline & LDL-C & $2.63(2.28,3.36)$ & $2.56(2.21,3.08)$ & $1.95(1.53,3.34)$ & 2.16 & 0.34 \\
\hline & HDL-C & $1.16(1.00,1.33)$ & $1.14(1.00,1.39)$ & I.2I $(0.98,1.45)$ & 0.27 & 0.87 \\
\hline \multirow[t]{4}{*}{ Atypical $(73|/ 609 /| 3 \mid)$} & $\mathrm{TC}$ & $3.95(3.35,4.59)$ & $3.94(3.43,4.55)$ & $4.01(3.44,4.75)$ & 0.91 & 0.63 \\
\hline & TG & $0.93(0.67,1.50)$ & $0.97(0.67, I .4 I)$ & $1.08(0.80,1.67)$ & 7.88 & 0.02 \\
\hline & LDL-C & $2.67(2.11,3.20)$ & $2.57(2.14,3.06)$ & $2.64(2.07,3.20)$ & 1.30 & 0.52 \\
\hline & HDL-C & $1.14(1.00,1.35)$ & $1.17(1.00,1.36)$ & $1.16(1.01,1.30)$ & 0.83 & 0.66 \\
\hline \multirow[t]{4}{*}{ Combined $(2|3 /| 48 / 40)$} & $\mathrm{TC}$ & $3.90(3.33,4.64)$ & $4.04(3.40,4.65)$ & $4.02(3.53,4.69)$ & 1.07 & 0.59 \\
\hline & TG & $0.97(0.65,1.38)$ & $1.04(0.73,1.39)$ & $1.19(0.82,1.67)$ & 3.95 & 0.14 \\
\hline & LDL-C & $2.62(2.14,3.11)$ & $2.68(2.17,3.20)$ & $2.83(2.15,3.20)$ & 0.91 & 0.63 \\
\hline & HDL-C & $1.15(1.00,1.38)$ & $1.21(1.00,1.45)$ & I.I3 $(0.97,1.4 \mathrm{I})$ & 2.67 & 0.26 \\
\hline
\end{tabular}

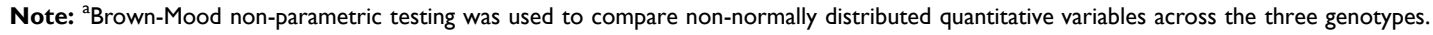

Abbreviations: HDL-C, high-density lipoprotein cholesterol; LDL-C, low-density lipoprotein cholesterol; TC, total cholesterol; TG, triglyceride.

antipsychotics are higher in women than in men, even at the same drug dose. ${ }^{30}$

APDs are classified as typical or atypical based on their ability to cause extrapyramidal side effects; ${ }^{31}$ randomized controlled trials comparing the two types of APD in schizophrenia have shown that the latter had similar or slightly superior efficacy and tolerability. ${ }^{31-34}$ Typical APDs cause more extrapyramidal side effects than atypical APDs; the latter are associated with higher risk for developing metabolic syndrome, which includes weight gain and dysregulation of glucose and lipid metabolism. ${ }^{35,36}$ The mechanism underlying atypical APD-induced dyslipidemia remains unclear, but is thought to involve peroxisome proliferator-activated receptor (PPAR), a transcription factor that regulates lipid and carbohydrate metabolism. As PPAR modulators, glimepiride, rosiglitazone, and fenofibrate showed beneficial TGlowering effects in atypical APD-treated mice. ${ }^{37}$ Previous studies have reported that TG levels showed a greater increase in patients treated with atypical APDs as compared to typical APDs. ${ }^{36,38}$ However, no differences were observed in our study. The reason for this discrepancy may be the large difference in group sizes of patients treated with typical ( $n=99)$ vs atypical ( $n=1476)$ APDs; the latter have greater efficacy and are associated with better treatment adherence and fewer adverse reactions than the former, and are therefore more frequently prescribed by clinicians.

ApoA1 and ApoB mutations were shown to predict the development of cardiovascular disease, $;^{39,40}$ and patients with schizophrenia have lower expression of ApoA1 compared to healthy subjects. ${ }^{41}$ Only a few studies to date 
have investigated the effect of APDs on ApoA1 and ApoB. As a matter of interest, ApoA1 and ApoB levels as well as ApoA1/ApoB and TC/HDL-C ratios were also analyzed in this study to explore the differences in safety and efficacy among different medications. But no differences were found (Tables S2-S6).

The ApoAl gene is a main site regulating lipids and lipoproteins expression, ${ }^{42,43}$ and the association between ApoA1 gene polymorphisms and lipid levels has been extensively studied. ${ }^{44,45}$ We found a significant association between the rs5072 polymorphism of ApoA1 and serum TG level in schizophrenia. Moreover, patients with the AA genotype had a higher TG level than those with the GG and GA genotypes. Rs5072 is in high linkage disequilibrium with rs2070665 and rs7116797; all three SNPs are located in regions with histone modifications that are characteristic of active promoters, and may regulate plasma TG level by enhancing the expression of ApoA1/C3/A4/A5 gene cluster. ${ }^{46}$

The present study had some limitations. Firstly, we compared lipid levels between patients treated with the two classes of APD but did not evaluate differences within each class (eg, olanzapine vs clozapine). Additional studies with a larger sample size are required to address this point Secondly, we focused on only one tagSNP in the association study, but should consider others in order to clarify the effect of gene interactions on lipid metabolism. Finally, previous studies have reported an association between ApoA1 gene polymorphisms and lipid levels. Drug therapy is a possible confounding factor in lipid abnormalities caused by ApoA1 variants; without a control group, it is unclear which variable contributed to the high TG levels in the patients. In order to address this issue, a cohort study with a small sample size was carried out to compare TG levels before and after APD treatment in patients with the rs5072 risk genotype (Table $\underline{\mathrm{S} 7)}$. The results showed that TG level was increased by the treatment, suggesting that this rs5072 polymorphism increases the risk of dyslipidemia, although a control group is needed to validate our conclusion.

\section{Conclusion}

Our results showed that schizophrenia patients are at high risk of developing dyslipidemia, which is influenced by multiple factors including sex and APD treatment regimen. We also identified that rs5072 in ApoA1 was associated with TG level in schizophrenia patients treated with APDs. These findings can guide clinical management strategies (eg, lifestyle modifications and pharmacotherapy) to prevent dyslipidemia in schizophrenia patients harboring this ApoA1 variant.

\section{Data Sharing Statement}

The datasets used and/or analyzed in this study are available from the corresponding author on reasonable request.

\section{Acknowledgments}

This work was supported by a project funded by Jiangsu Pharmaceutical Association-Tianqing Hospital Pharmacy (no. Q2018061). The authors also thank Charlesworth Author Services for editing and proofreading the article.

\section{Author Contributions}

All authors made a significant contribution to the work reported, whether that is in the conception, study design, execution, acquisition of data, analysis and interpretation, or in all these areas; took part in drafting, revising or critically reviewing the article; gave final approval of the version to be published; have agreed on the journal to which the article has been submitted; and agree to be accountable for all aspects of the work.

\section{Disclosure}

The authors declare that they have no conflicts of interest.

\section{References}

1. Miyamoto S, Miyake N, Jarskog LF, Fleischhacker WW, Lieberman JA. Pharmacological treatment of schizophrenia: a critical review of the pharmacology and clinical effects of current and future therapeutic agents. Mol Psychiatry. 2012;17(12):12 06-1227. doi: $10.1038 / \mathrm{mp} .2012 .47$

2. Lieberman JA. Is schizophrenia a neurodegenerative disorder? A clinical and neurobiological perspective. Biol Psychiatry. 1999;46 (6):729-739. doi:10.1016/S0006-3223(99)00147-X

3. Insel TR. Rethinking schizophrenia. Nature. 2010;468(7321):18 7-193. doi:10.1038/nature09552

4. Tandon R, Keshavan MS, Nasrallah HA. Schizophrenia, "Just the Facts" What we know in 2008. 2. Epidemiology and etiology. Schizophr Res. 2008;102(1):1-18. doi:10.1016/j.schres.2008.04.011

5. Charlson FJ, Ferrari AJ, Santomauro D, et al. Global epidemiology and burden of schizophrenia: findings from the global burden of disease study 2016. Schizophr Bull. 2018;44(6):1195-1203. doi:10.1093/schbul/sby058

6. Zhang J, Malhotra AK. Pharmacogenetics and Antipsychotics: therapeutic Efficacy and Side Effects Prediction. Expert Opin Drug Metab Toxicol. 2011;7(1):9-37. doi:10.1517/17425255.2011.532787

7. Stroup TS, Gray N. Management of common adverse effects of antipsychotic medications. World Psychiatry. 2018;17(3):341-356. doi:10.1002/wps.20567

8. Baandrup L. Polypharmacy in schizophrenia. Basic Clin Pharmacol Toxicol. 2020;126(3):183-192. doi:10.1111/bcpt.13384

9. Correll CU, Frederickson AM, Kane JM, Manu P. Does antipsychotic polypharmacy increase the risk for metabolic syndrome. Schizophr Res. 2007;89(1):91-100. doi:10.1016/j.schres.2006.08.017

10. Melkersson K, Dahl ML. Adverse metabolic effects associated with atypical antipsychotics: literature review and clinical implications. Drugs. 2004;64(7):701-723. doi:10.2165/00003495-200464070-00 003 
11. Olose EO, Edet J, Igwe MN, Chukwujekwu DC, Aguocha MC, Uwakwe R. Dyslipidaemia and Medical Outcome (Health Related Quality of Life) in Patients with Schizophrenia Taking Antipsychotics in Enugu, Nigeria. Psychiatry J. 2017;2017 (4):9410575. doi:10.1155/2017/9410575

12. Cai HL, Tan QY, Jiang P, et al. A potential mechanism underlying atypical antipsychotics-induced lipid disturbances. Transl Psychiatry. 2015;5(10):e661. doi:10.1038/tp.2015.161

13. Kim SF, Huang AS, Snowman AM, Teuscher C, Snyder SH. Antipsychotic drug-induced weight gain mediated by histamine H1 receptor-linked activation of hypothalamic AMP-kinase. Proc Natl Acad Sci U S A. 2007;104(9):3456-3459. doi:10.1073/ pnas.0611417104

14. Reynolds GP, Hill MJ, Kirk SL. The 5-HT2C receptor and antipsychoticinduced weight gain - mechanisms and genetics. J Psychopharmacol. 2006;20(4_suppl):15-18. doi:10.1177/ 1359786806066040

15. Liao B, Cheng K, Dong S, Liu H, Xu Z. Effect of apolipoprotein A1 genetic polymorphisms on lipid profiles and the risk of coronary artery disease. Diagn Pathol. 2015;10(1):102. doi:10.1186/s13000015-0328-7

16. La Y, Wan C, Zhu H, et al. Decreased levels of apolipoprotein A-I in plasma of schizophrenic patients. J Neural Transm. 2007;114 (5):657-663. doi:10.1007/s00702-006-0607-2

17. Song X, Li X, Gao J, et al. APOA-I: a possible novel biomarker for metabolic side effects in first episode schizophrenia. PLoS One. 2014;9(4):e93902. doi:10.1371/journal.pone.0093902

18. Stefansson H, Ophoff RA, Steinberg S, et al. Common variants conferring risk of schizophrenia. Nature. 2009;460(7256):744-747. doi:10.1038/nature08186

19. Wang ZW, Black DW, Andreasen NC, Crowe RR, Linkage A. Study of Chromosome 11q in Schizophrenia. Arch Gen Psychiatry. 1993;50 (3):212-216. doi:10.1001/archpsyc.1993.01820150062006

20. Klar AJS. A Genetic Mechanism Implicates Chromosome 11 in Schizophrenia and Bipolar Diseases. Genetics. 2004;167 (4):1833-1840. doi:10.1534/genetics.104.028217

21. De Luis DA, Izaola O, Primo D, Aller R. Role of rs670 variant of APOA1 gene on lipid profile, insulin resistance and adipokine levels in obese subjects after weight loss with a dietary intervention. Diabetes Res Clin Pract. 2018;142:139-145. doi:10.1016/j. diabres.2018.05.040

22. Bora K, Pathak MS, Borah P, Hussain MI, Das D. Single nucleotide polymorphisms of APOA1 gene and their relationship with serum apolipoprotein A-I concentrations in the native population of Assam. Meta Gene. 2016;7:20-27. doi:10.1016/j.mgene. 2015.10.005

23. Joint Committee for Revision of Chinese guidelines for prevention and treatment of dyslipidemia in adults. Chinese Guidelines on Prevention and Treatment of Dyslipidemia in Adults (2016 Revision). Chine Circulation J. 2016;31(10):937-953. doi:10.3969/ j.issn.1000-3614.2016.10.001

24. Correll CU, Rummelkluge C, Corves C, Kane JM, Leucht S. Antipsychotic combinations vs monotherapy in schizophrenia: a meta-analysis of randomized controlled trials. Schizophr Bull. 2009;35(2):443-457. doi:10.1093/schbul/sbn018

25. Qiu H, He Y, Zhang Y, et al. Antipsychotic polypharmacy in the treatment of schizophrenia in China and Japan. Australian $N$ Zealand J Psychiatry. 2018;52(12):1202-1212. doi:10.1177/ 0004867418805559

26. Ortizorendain J, Obeso SC, Colungalozano LE, Hu Y, Maayan N, Adams CE. Antipsychotic combinations for schizophrenia. Cochrane Database Sys Rev. 2017;6(2):CD009005. doi:10.1002/14651858. CD009005.pub2

27. Lally J, Maccabe JH. Antipsychotic medication in schizophrenia: a review. Br Med Bull. 2015;114(1):169-179. doi:10.1093/bmb/ldv017
28. Seeman MV. Secondary effects of antipsychotics: women at greater risk than men. Schizophr Bull. 2009;35(5):937-948. doi:10.1093/ schbul/sbn023

29. Knopp RH, Paramsothy P, Retzlaff BM, et al. Sex differences in lipoprotein metabolism and dietary response: basis in hormonal differences and implications for cardiovascular disease. Curr Cardiol Rep. 2006;8(6):452-459. doi:10.1007/s11886-006-0104-0

30. Aichhorn W, Marksteiner J, Walch T, et al. Age and Gender Effects on Olanzapine and Risperidone Plasma Concentrations in Children and Adolescents. J Child Adolesc Psychopharmacol. 2007;17 (5):665-673. doi:10.1089/cap.2006.0045

31. Zhang J, Gallego JA, Robinson DG, Malhotra AK, Kane JM, Correll CU. Efficacy and safety of individual second-generation vs first-generation antipsychotics in first episode psychosis: a systematic review and meta-analysis. Int $J$ Neuropsychopharmacol. 2013;16 (6):1205-1218. doi:10.1017/S1461145712001277

32. Grunder G, Heinze M, Cordes J, et al. Effects of first-generation antipsychotics versus second-generation antipsychotics on quality of life in schizophrenia: a double-blind, randomised study. Lancet Psychiatry. 2016;3(8):717-729. doi:10.1016/S2215-0366(16)00085-7

33. Jeon SW, Kim YK. Unresolved issues for utilization of atypical antipsychotics in schizophrenia: antipsychotic polypharmacy and metabolic syndrome. Int J Mol Sci. 2017;18(10):2174. doi:10.3390/ ijms 18102174

34. Leucht S, Corves C, Arbter D, Engel RR, Li C, Davis JM. Secondgeneration versus first-generation antipsychotic drugs for schizophrenia: a meta-analysis. Lancet. 2009;373(9657):31-41. doi:10.1016/ S0140-6736(08)61764-X

35. Meltzer HY. Update on Typical and Atypical Antipsychotic Drugs. Annu Rev Med. 2013;64(1):393-406. doi:10.1146/annurev-med -050911-161504

36. Wu R, Zhao J, Liu Z, et al. Effects of typical and atypical antipsychotics on glucose-insulin homeostasis and lipid metabolism in firstepisode schizophrenia. Psychopharmacology. 2006;186(4):572-578. doi:10.1007/s00213-006-0384-5

37. Arulmozhi DK, Dwyer DS, Bodhankar SL. Antipsychotic induced metabolic abnormalities: an interaction study with various PPAR modulators in mice. Life Sci. 2006;79(19):1865-1872. doi:10.1016/ j.1fs.2006.06.016

38. Wu R, Zhao J, Zhai J, Guo X, Guo W. Sex difference in effects of typical and atypical antipsychotics on glucose-insulin homeostasis and lipid metabolism in first-episode schizophrenia. J Clin Psychopharmacol. 2007;27(4):374-379. doi:10.1097/JCP.0b013e3180cac8db

39. Andrikoula M, Mcdowell IFW. The contribution of ApoB and ApoA1 measurements to cardiovascular risk assessment. Diabetes Obes Metab. 2008;10(4):271-278. doi:10.1111/j.1463-1326.2007.00714.x

40. Vlad C, Foia L, Popescu R, et al. Apolipoproteins A and B and PCSK9: nontraditional Cardiovascular Risk Factors in Chronic Kidney Disease and in End-Stage Renal Disease. Exp Diabetes Res. 2019;2019:6906278. doi:10.1155/2019/6906278

41. Wu X, Huang Z, Wu R, et al. The comparison of glycometabolism parameters and lipid profiles between drug-naïve, first-episode schizophrenia patients and healthy controls. Schizophr Res. 2013;150 (1):157-162. doi:10.1016/j.schres.2013.07.051

42. Feng DW, Ma RL, Guo H, et al. Association of APOA1 gene polymorphisms (rs670, rs5069, and rs2070665) with dyslipidemia in the Kazakhs of Xinjiang. Genetics Mol Res. 2016;15(2): gmr.15028094. doi:10.4238/gmr.15028094

43. Ou HJ, Huang G, Liu W, et al. Relationship of the APOA5/A4/C3/A1 gene cluster and APOB gene polymorphisms with dyslipidemia. Genetics Mol Res. 2015;14(3):9277-9290. doi:10.4238/2015.August.10.8

44. Bora K, Pathak MS, Borah P, Hussain MI, Das D. Association of theApolipoprotein A-IGene polymorphisms with cardiovascular disease risk factors and atherogenic indices in patients from Assam, Northeast India. Balkan J Med Genetics Bjmg. 2017;20(1):59-70. doi:10.1515/bjmg-2017-0002 
45. Xu L, Zhou Y, Yao J, et al. Apolipoprotein A1 polymorphisms and risk of coronary artery disease: a meta-analysis. Arch Med Sci. 2017;13(4):813-819. doi:10.5114/ aoms.2017.65233
46. Suarezsanchez F, Klunderklunder M, Valladaressalgado A, et al. APOA5 and APOA1 polymorphisms are associated with triglyceride levels in Mexican children. Pediatr Obes. 2017;12(4):330-336. doi:10.1111/ijpo.12147

\section{Publish your work in this journal}

Neuropsychiatric Disease and Treatment is an international, peerreviewed journal of clinical therapeutics and pharmacology focusing on concise rapid reporting of clinical or pre-clinical studies on a range of neuropsychiatric and neurological disorders. This journal is indexed on PubMed Central, the 'PsycINFO' database and CAS, and is the official journal of The International Neuropsychiatric Association (INA). The manuscript management system is completely online and includes a very quick and fair peer-review system, which is all easy to use. Visit http://www.dovepress.com/testimonials.php to read real quotes from published authors.

Submit your manuscript here: https://www.dovepress.com/neuropsychiatric-disease-and-treatment-journal 